\title{
EXPERIMENTAL AND FEM SIMULATION ANALYSIS OF CLOSED-DIE FORGING PROCESS ON COMPANION FLANGE IN THE DRIVING AUTOMOTIVE SYSTEM
}

\author{
LE TRUNG KIEN ${ }^{1 *} \&$ NGUYEN QUANG THANG ${ }^{2}$ \\ ${ }^{I}$ School of Mechanical Engineering, Hanoi University of Science and Technology, Hanoi, Vietnam \\ ${ }^{2}$ Hanoi Industrial Textile Garment University, Hanoi, Vietnam
}

\begin{abstract}
The forging process is presented as a possible solution as it allows the production of parts with good surface finish and mechanical properties. In this paper, the new forging process for forming the Companion flange in the automotive driving system is proposed. The key technology of the new forging process is focused on the finish-forging design. The closed-die forging without a flash process for the finish-forging is proposed, by which the material utilization rate is enhanced greatly. The proper forming includes three steps: upsetting, performing, and finish forging. The 3D finite element method (FEM) for simulation of the forging process is also presented. In this study, the usage of finite element software has been applied to model a forming operation. Based on the simulation results, the parts are successfully done on a 1000 tons hot forging crank-stamping press. The experimental forged samples are observed in good conformity with the simulated models. The industrial application of new technology is shown, too

KEYWORDS: Closed-Die Forging, Metal Forming, Finite Element, Flash, Under-Filling, Burry
\end{abstract}

Received: Jun 10, 2020; Accepted: Jun 30, 2020; Published: Aug 01, 2020; Paper Id.: IJMPERDJUN2020558

\section{INTRODUCTION}

Metal forming is widely used in the manufacturing process noted for its minimum waste and dimensional precision, and it usually improves the mechanical properties of the formed part.

The three tasks of bulk-forming, including extrusion and die forging. Die forging is divided into closed-die with flash and without flash. Extrusion is often applied for aluminum [1,4]. Besides, the bulk stamping in an opened-die has been studied and widely used in the forming industry. Meanwhile, very few studies and applications of bulk stamping in a closed-die have been performed. After die forging, the microstructure and mechanical properties of the metal are improved effectively [2]. Studies of the material structure, hardness, and mechanical properties after forming processes have also been performed [1, 3]. However, the forming sequence and design for new products is not a straightforward task, and it requires many trials and adjustments to achieve the optimal process. In the area of optimization forming sequence and forging die design, substantial investigations have been carried out by many researchers using various tools and techniques such as finite element method (FEM) [5,6,7], experimental method.

This study aims to find out the forming sequence for complex geometry forging parts. If the initial billet is formed directly, some serious defects will appear in the finish-forging part, such as filling discontent, fold, crack defects, etc. Thus, to get a high quality forging part, the die forging process usually has several stages. The researchers want to find a way that the required number of forging stages, the good shape of forging dies of every part. But for the forging part with irregular shapes, now there are still no complete theory and algorithm to solve the 
die forging design problem.

Recently, the designer still relies on experience combined with finite element simulation for researching some complex geometry forging parts. Some successful research examples were reported such as a rear axle bracket for automobile [9], steering knuckle of the truck [10], gear pumps [8,11], sprocket wheel [12], Using FEM simulation technology, the distributions of stress and strain are obtained, and the influences of parameters to plastic deformation of the workpiece are analyzed. Through the results of the experiment, it is founded that the simulation results fit the actual forming process well. This is a right and modern way of being applied in practice.

The Companion Flange is an important and high dimensional accuracy part of the automotive driving system. Now, automobile parts are mainly formed by the closed-die forging process with flash $[9,10,12,13]$ or cold forging [14]. The forging process of this part is the multi-stages and complex forging process. Therefore, the study of closed-die forging without flash is really necessary.

Advanced hot forging processes have been proposed to realize the demands. Doege and Bohnsack [2] and Behrens et al. [15] reported advanced tool concepts for precision hot forging. Process variables of the closed-die forging of the bevel gear were selected to be the pressing type, punch location, and billet diameter was made by Song and Im [16]. Dean, T.A. et al. [17] analyzed hot precision forging process of the straight bevel gear is simulated numerically using finite volume method and computer-aided design/computer-aided engineering technology used to optimize the forging process to maximize the mechanical strength, minimize material scrap, and hence reduce the overall cost of manufacture. Yong-Jin Choi et al. [12] compare the environmental effects of the hot forging process and machining process for manufacturing sprocket wheels by simulating.

The closed-die forging without flash can improve material utilization and increase the deform uniformity [11]. But there are some problems that should be resolved in the closed-die forging without flash: high billet accuracy, constant tool temperature and forging temperature, low die life, etc. Thus, the stamping technology used closed-die is currently implemented very little. In forging two main reasons cause to shot tool life: damage which limits die life occurs when the die steel strength cannot withstand the load during the forging process and die wear when the material is actually removed from the die surface by pressure and sliding of the deforming material [18]. Nikolai Biba et al. [19] using the FEM code QForm, the possibility of the die wear calculation provides forging technology optimization by minimization of the die wear. Damage accumulation theory can be successfully applied for prediction of die fracture and increasing tool life. Siamak Abachi et al. [20] used the finite element method to simulate the die wear. By comparing the numerical results with the measurement taken from the worn die, the wear coefficient has been evaluated for different points of the die surface. Finally,the value of the wear coefficient is suggested. These studies just focus on simulation, and it is not verified by experiments.

H.M.T. Khaleed et al. Presented three-dimensional FEM analysis and experimental flashless cold forging and temperature distribution of aluminum front and back hubs of Autonomous Underwater Vehicle (AUV) propeller [21]. However, the research work-part is still simple, and the pressing force is not large because of using a C-type machine (done on a 100-ton C-type machine), leading to low accuracy.

In this paper, the new closed-die forging without the flash process of the Companion Flange is proposed. The application of the finite element numerical simulation method in the metal forming process can provide detailed and 
reliable information, by which we can successfully optimize the forming parameters and the design of dies. Using the finite element method for simulation of analysis of technology steps, determine critical strain, analyze metal flow, and forecast the causes of such defects in parts. Based on simulation results, we can conduct experimental verification of results.

\section{RESEARCH OBJECT AND METHOD.}

\section{Research Subjects}

The Companion Flange is a typical kind of Flange. Its weight is $1.23 \mathrm{~kg}$. 3D modeling and 2D drawing of Companion Flange are shown in Figure 1 and Figure 2. According to its geometric features, Companion Flange is divided or classified into sections 2 in this paper, including Flange and body, as shown in Figure 1. The Flange is short and wide; the body is complex in geometry with a narrow hole.

The Companion Flange is a complex class forging huge deformation parts. Its forging characteristics are:

- Metal flow into the body most fastly, and this area is prone to filling discontent and fold.

- $\quad$ Flange is filled with metal at last, and the flange edge is the most difficult to be filled in.

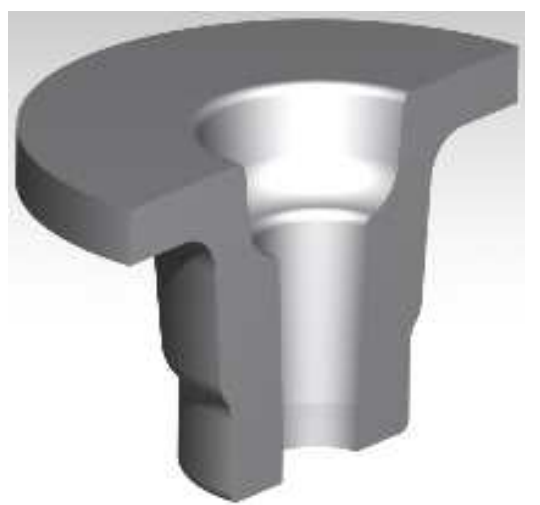

Figure 1: 3D Modeling of Companion Flange.
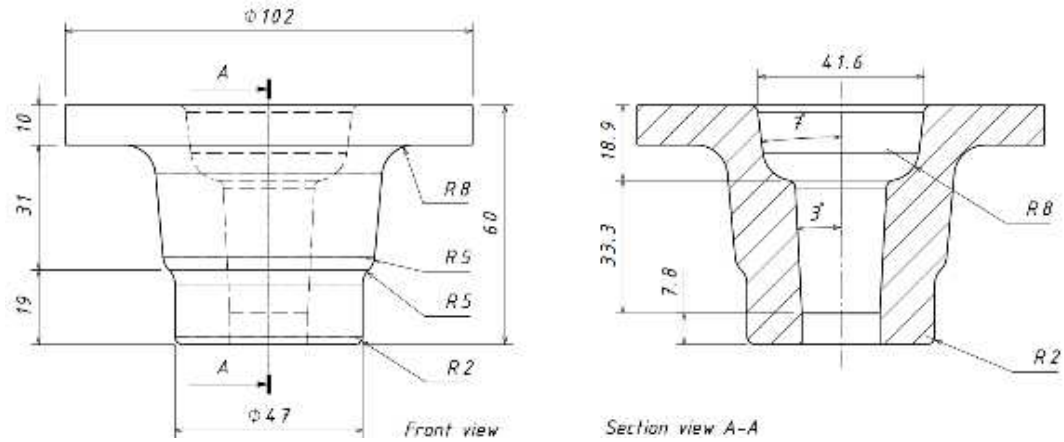

Figure 2: 2D Drawing of Companion Flange.

The material for forging was case hardening steel DIN 17210 (16MnCr5). The chemical composition of this steel is shown in Table 1. 
Table 1: Physical Parameters of used Materials

\begin{tabular}{|l|c|c|c|c|c|c|}
\hline \multicolumn{6}{|c|}{ Chemical Composition [Percent by Weight] } \\
\hline & C & Mn & Si & Cr & P & S \\
\hline $\min$ & 0.14 & 1.1 & 0.17 & 0.8 & & \\
\hline $\max$ & 0.19 & 1.4 & 0.37 & 1.1 & 0.035 & 0.035 \\
\hline
\end{tabular}

\section{Forging Process}

The traditional die forging process of Companion Flange with flash is: Shearing - Upsetting - Preforging - Finish forging Piercing the hole -Trimming the flash and Inspecting. Closed-die forging with flash has the advantages of wide technological applicability and high die life. But flash size is not easy to control, so it has a low material utilization rate.

New technological process and manufacturing steps of parts are defined by selecting workpiece with diameter $\phi$ $50 \mathrm{~mm}$, after upsetting and preforming, then finish forging in closed-die for filling metal in the Flange. After piercing the hole, the part is inspected to ensure zero defects. Companion Flange can be formed by one-heating forging on the hot dieforging press. Closed-die forging process without a flash of Companion Flange includes six steps (see Figure 3).

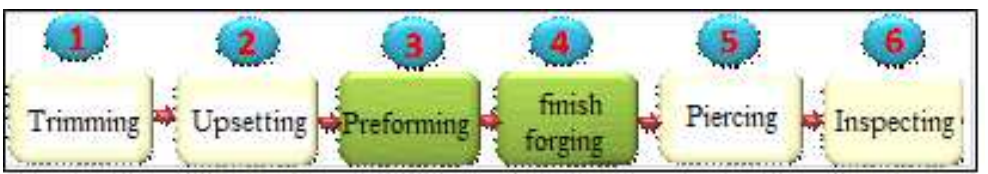

Figure 3: Forging Process of Companion Flange.

\section{Simulation Process}

3D modeling of closed-die forging without flash is shown in Figure 4. The material for forging was case steel DIN 17210 (16MnCr5). Tensile strength $\geq 610 \mathrm{MPa}$. The material properties chosen for the current study are shown in Table 2 .

Table 2: The Material Property of the Workpiece, Die and Punch

\begin{tabular}{|l|c|c|c|}
\hline \multicolumn{1}{|c|}{ Parameters } & Workpiece & Die & Punch \\
\hline Material Type & DIN 17210 & SKD61 & SKD61 \\
\hline Young's Modulus (GPa) & 70 & 210 & 210 \\
\hline Poission's Ratio & 0.35 & 0.33 & 0.33 \\
\hline Hardness (HRC) & 24 & 59.9 & 67 \\
\hline
\end{tabular}

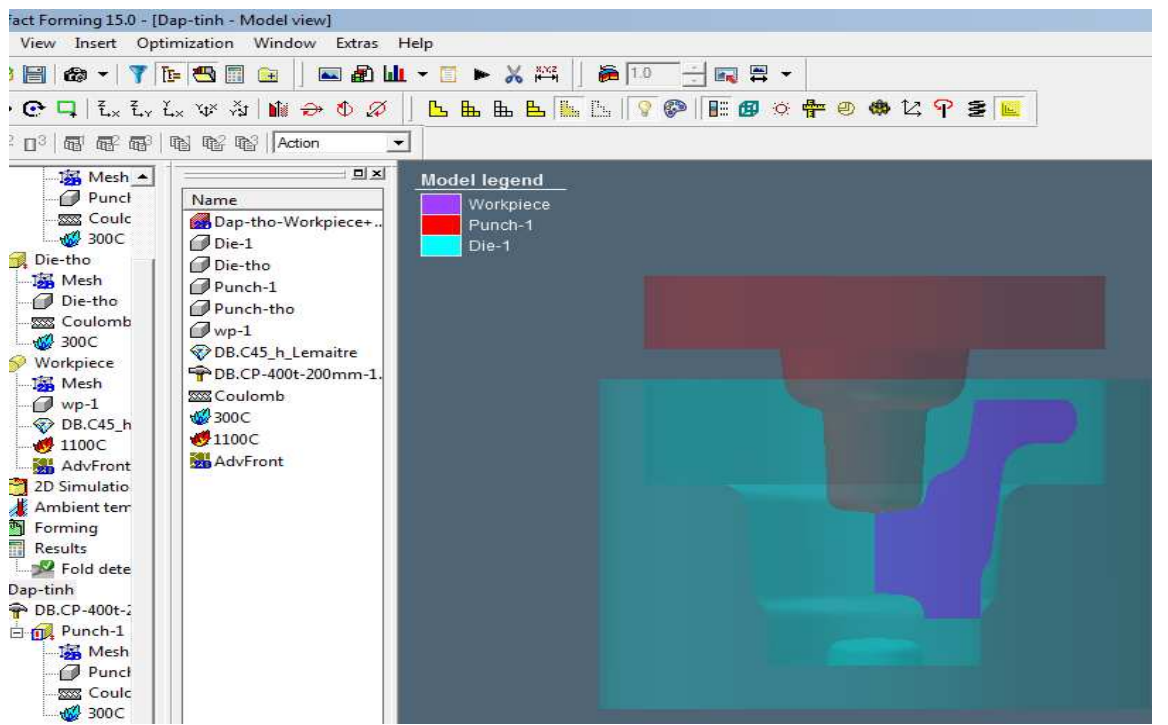

Figure 4: Simulation Models of Die and Punch Assembly for the Companion Flange. 
Using the software to run the simulation, the results are observed. The mathematical equations for the workpiece dimensions to achieve the forging without flash are developed as follows: It is assumed that the volume of the workpiece is equal to the volume of the cavity to fill. Hence the volume of the geometry of the workpiece $\left(\mathrm{V}_{\mathrm{wp}}\right)$ and that of the final forging $\left(\mathrm{V}_{\mathrm{f}}\right)$ are equated. If no burry is observed, then under-filling is checked for the process. If no under-filling is found, then stops the process; otherwise, the process is repeated till no under-filling is achieved. The optimum length and radius of the workpiece can be obtained from the numerical simulation. Substituting the volume of the workpiece with diameter $\mathrm{d}$ $=50 \mathrm{~mm}$, we get the values of length $\left(\mathrm{L}_{1}\right)$. The numerical simulation performs three types of workpiece configuration with the different height from $79.7 \mathrm{~mm}, 80.9 \mathrm{~mm}$, and $81.6 \mathrm{~mm}$ (respectively initial weight 1220 grams, 1240 grams, and 1250 grams).

Die was calculated based on the principle of closed-die process and dimension of the designed product. Because the Companion Flange is axisymmetric, so maybe $1 / 4$ or $1 / 2$ of the model can be used on FEM simulation to get an accurate result and minimize analysis time.

The velocity of the punch is $250 \mathrm{~mm} / \mathrm{sec}$. Friction between parts and die is 0.25 , and between the parts and punch is 0.15 [3]. The initial temperature of the workpiece is $1,130 \pm 50^{\circ} \mathrm{C}$, punch, and die is $25^{\circ} \mathrm{C}$. Elastic-plastic material model. Punch stroke is $69.9 \mathrm{~mm}$, the number of steps is 100 , and the step increment is 10 . For the die, interpolation force tolerance is 0.0001 , the bottom surface of the die is constrained in $\mathrm{X}, \mathrm{Y}$ and $\mathrm{Z}$ directions, starting step number is 1 , the number of simulation step is 1 , step increment 1 , and maximum elapsed process time is $1 \mathrm{sec}$. The work-pieces would have meshed of quadrilateral elements, suitable for die full-filled process, the number of elements used for workpiece is 2000 , for punch 50500 and for die 50500. The simulation models for die, punch, and workpiece are shown in Figure 4. Numerical simulation boundary conditions were given in table 3 below.

Table 3: Boundary Conditions for Numerical Simulation

\begin{tabular}{|l|c|}
\hline \multicolumn{1}{|c|}{ Parameters, Characteristics } & Values \\
\hline Work-piece temperature $\left({ }^{\circ} \mathrm{C}\right)$ & $1,130 \pm 50$ \\
\hline Friction, $f$ & \\
\hline between parts and die & 0.25 \\
\hline between the parts and punch & 0.15 \\
\hline Fixed and discrete rigid & 100 \\
\hline
\end{tabular}

\section{Experimental Work}

As aforementioned in the introduction, the companion flange is an important part of the automotive driving system. Nowadays, there are various methods to manufacture companion flange products, mostly by closed-die technique with flash. The workpieces are prepared by Cut Machine with an accurate size.

After cutting the workpieces by the designed dimension, they are heated in the oven before processing. The lower and upper die is created by the dimension is calculated and designed by Solid-works.The dies are made of SKD61 steel, as shown in Figure 5. The pressing machine used for the experiment is crank press machine FP1000G with capacity 1,000 tons. 




Figure 5: Press Machine and Forging Die used for Experiment: Press Machine (a) and Forging Die (b).

\section{RESULTS AND DISCUSSIONS}

\section{Effect of Initial Height in Simulation}

The under-filling and flash are observed for the companion flange. For three different initial height from 79.7mm, 80.9mm, and $81.6 \mathrm{~mm}$ (cases I, II, and III respectively). Figure 6, Figure 7 and Figure 8 show the views of the corresponding forged models. For the case I, slight under-filling is observed at the corners of flanger, too, as evident from Figure 6. For case II, the metal fills at the corners of the flanger, as shown in Figure 7. Figure 8 shows the burry, which is observed in the flash zone for case III. Case II seems the best option as it has the minimum flash, as evident from Table 4. Hence it is concluded that case II is the optimum workpiece



Figure 6: The View of Companion Flange Formation for the Case I.



Figure 7: The View of Companion Flange Formation for Case II. 


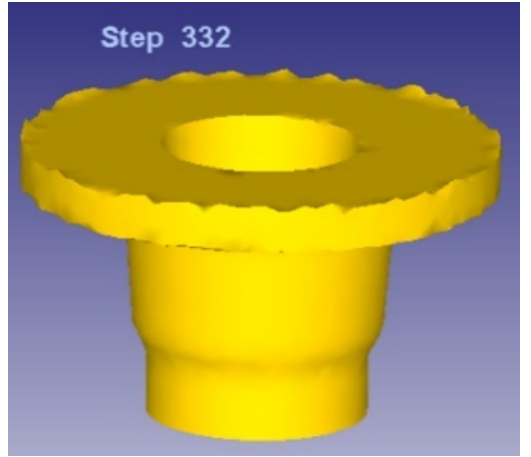

Figure 8 : The View of Companion Flange Formation for Case III.

\begin{tabular}{|c|c|l|}
\hline \multicolumn{3}{|c|}{ Table 4: Boundary Conditions for Numerical Simulation } \\
\hline Case & Initial Height $(\mathbf{m m})$ & \multicolumn{1}{c|}{ Flash } \\
\hline I & 79.7 & Under-filling \\
\hline II & 80.9 & Filling \\
\hline III & 81.6 & Burry \\
\hline
\end{tabular}

\section{Analysis of Force in Simulation}

The choice of billet dimensions is very important for the design of the technological parameters of closed-die forging. A close-up representation of the material flow through the closed-die is carried out by providing the force-stroke diagrams of the process at several stages of the die stroke. Three basic alternatives to initial height have been considered. It is concluded that case II is the optimum workpiece. Sothe analysis of force in simulation with case II. The forming sequence of the workpiece from upsetting to the closed-die as well as the corresponding force-stroke diagrams are shown in Figure 9, respectively. The magnitude of the forging force in the process can be obtained from the corresponding force-stroke diagram. The companion flange forging process can be divided into five steps. Step 1 is cutting, Step 2 (A) is upsetting with force is low (9.0 tons), from step 3 (B) - metal flows into the pre-forging die inside. Until step 4 - in closed-die - (C), metal start to fill edges of Flange, step 5 is piecing the hole. In step 3 (B), the compressive force is almost not large (38.9 tons). At step 4 (C), the metal begins to touch the die-wall at Flange, and the force begins increasing rapidly. At the end of step 4 (D) is a die full-filled period, and the force immensely increased (581.0 tons).

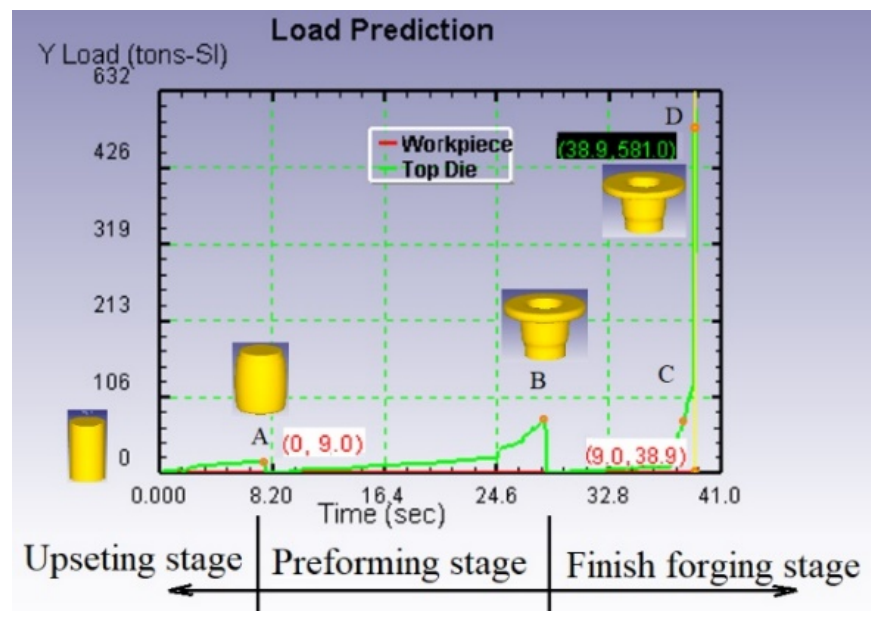

Figure 9: Force-Step Diagram and Forging Process for Simulation with v=1mm/s. 


\section{Analysis of Stress in Simulation}

Stress is a characteristic parameter for energy process development in forming techniques. In deformation areas that have a large strain, the impedance will occur high-stress field. Stress field distribution on workpieces with Initial height $80.9 \mathrm{~mm}$ has shown step by step in Figure 10.

a, strain effective


b, stress effective



c, Stress - max principal

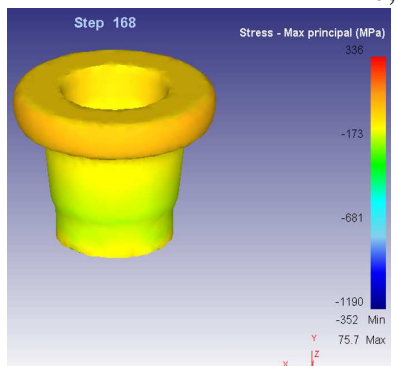

$50 \%$ of the simulation process

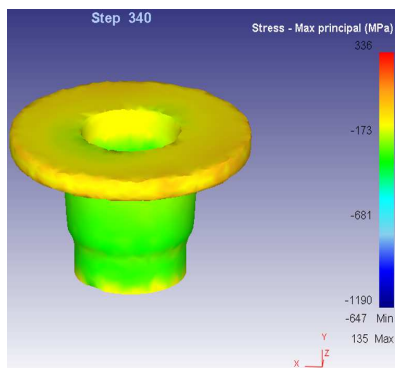

$100 \%$ of the simulation process

Figure 10: Results of Computer Simulation at the Various Stages of the Simulation Process in Step 4 with Different Initial Height 80.9mm.

The final filling in the die cavity was ended when the fillets on the Flange was filled. During the forging process, stress concentrated mostly on interface areas and tended to focus on the center area of the product. Results show that the highest effective plastic strains were at the sidewalls of the punch, which make the hole in the part. The lowest effective plastic strain was in the area near the body of the drop forging. As shown in Figure 10, the intersection between the cylinder and the flange material areas take the highest stress, especially in the bottom of the Flange, where the workpieces initially touch the die wall, since the magnitude of forging force increase more and more until the end of the process. Further results of effective stress show that the highest values happened to be in the area of the Flange and in the lower part of a Companion Flange.

\section{Metal Flow in the Deformation Process}

The process of deformation in the forging process is quite complicated. The change of metal flow depends on the direction of force applied. In this case, the metal direction of the metal flow is perpendicular to the stroke direction. Figure 11 shows the velocity vector of metal flow during step deformation. It is easy to see that the metal flow runs evenly and stably, 
forming metal fibers. Based on numerical simulation, it is possible to study the metal flow in forging and other metalworking methods to compare and judge the compressive forces and metal flow in each field.

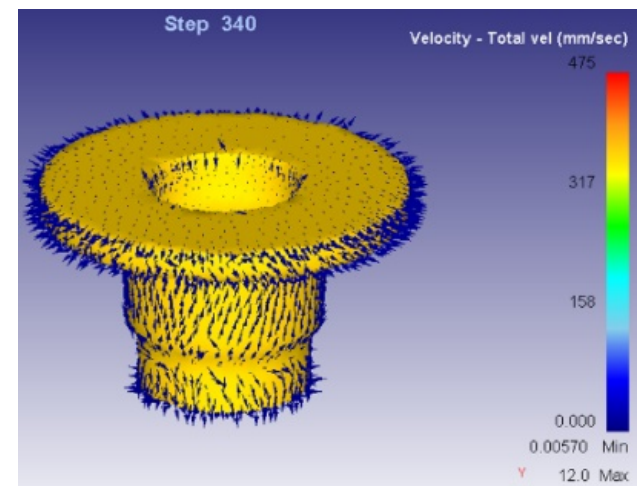

Figure 11: The Velocity Vector of Metal Flow during Steps Deformation by Simulation.

\section{Validation of the Simulation Results by Experimental}

For starting the simulation, it is necessary to properly define requires the proper definition of the input data. For starting a simulation of a companion flange, the following input data were defined.

The design of preforming billet is a difficult point in the pre-forging of companion flange. In the process of the closed-die forging without the flash of companion flange, the initial height is chosen $79.7 \mathrm{~mm}, 80.9 \mathrm{~mm}$, and $81.6 \mathrm{~mm}$ (Figure 12). The under-filling are observed for the Flange, for three different initial height. With an initial height of 79.7 $\mathrm{mm}$, the lower part of the part has been filled out firstly, but in the Flange was not filled. With an initial height of $81.6 \mathrm{~mm}$, the simulation results show that stress in objects greatly increases. Experimental results show that metal flows into the gap of the dielock causing burry and breaking die (Figure 13). According to the experiment result, the obtained product with an initial height of $80.9 \mathrm{~mm}$ is qualified for the requirement about shape and dimension (Figure 14).

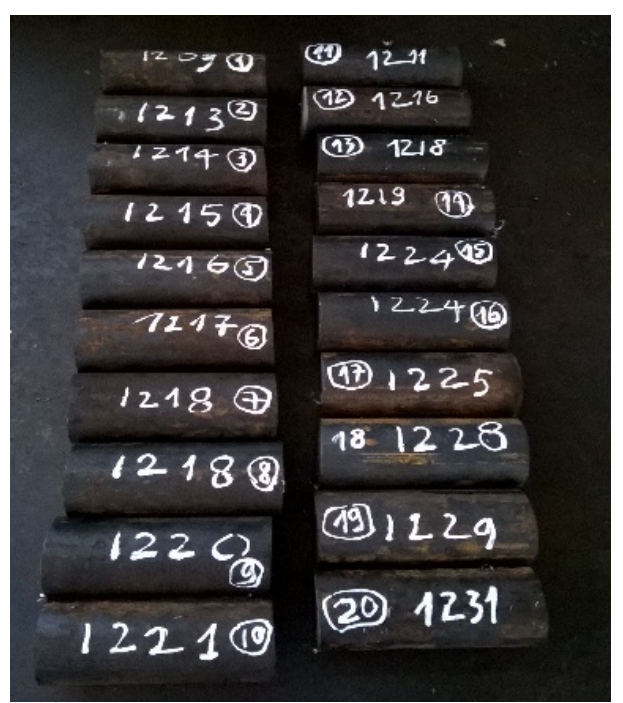

Figure 12: Billet for Experimental Forging with Initial Height 80.9 mm. 
a)

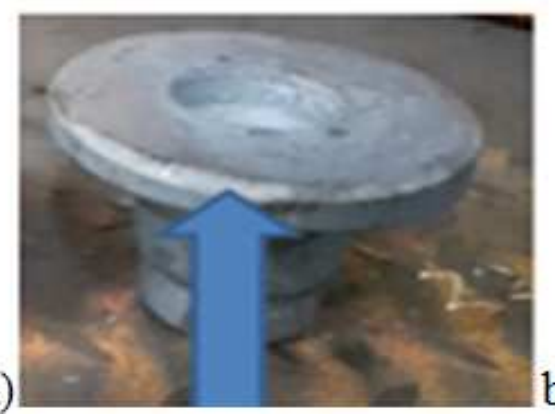

b)

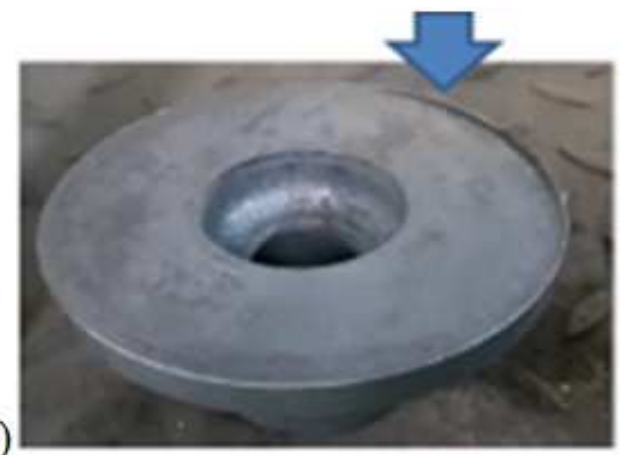

Figure 13: Effect of Initial Height: Under-Filling with Initial Height (a) and Burry with Initial Height $81.6 \mathrm{~mm}(\mathrm{~b})$.
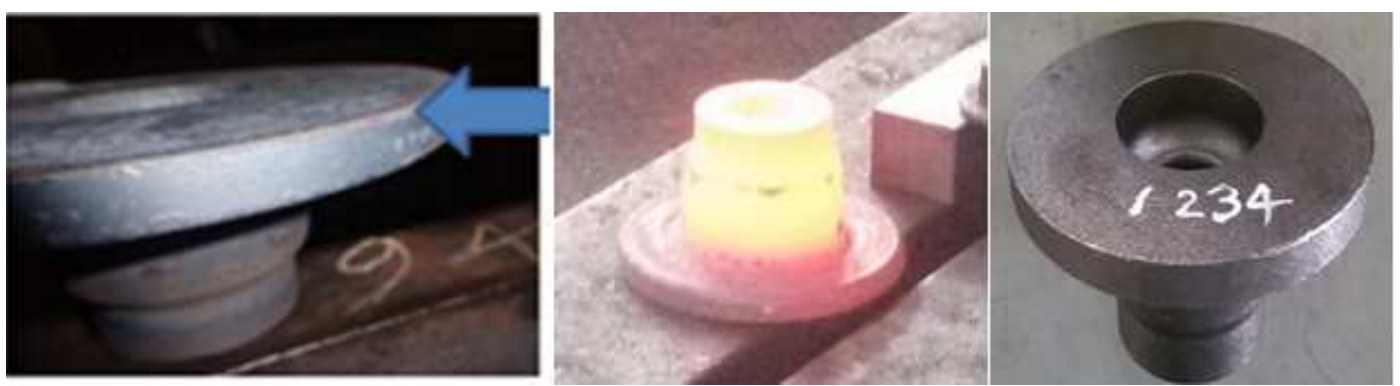

Figure 14: Effect of Initial Height with 80.9 mm.

From the experimental result, it can be seen the product is qualified for the requirement about shape, dimension. After numerical simulation and experimental analysis, closed-die forging without flash is considered for manufacturing companion flange products. In order to substantiate the simulation results, the value of the force needed for the closed-die forging stage is calculated using the corresponding force-time diagram and compared with its experimental counterpart.

\section{CONCLUSIONS}

Fabricating companion flange by closed-die forging without flash technique presents some difficulties such as harming die longevity since the high impact force. Ensuring the correct volume of the workpiece is extremely necessary. If there is excess volume, a die break will occur and creates low accuracy of dimension. Therefore, if we apply advanced closed-die forging technologies to manufacture, it can help increase durability and lifetime, reduce machining cost, and save more materials. Based on numerical analysis such as stress distribution, metal flow, and the effect of initial height, companion flange forging process, suitable parameters were chosen to perform experiments. The results showed a close agreement between the numerical simulation and experimental analysis of the companion flange.

\section{REFERENCES}

1. Osama Mohamed Irfan, 2015. Experimental Study for Characterization of Mechanical Behavior of Al/SiCp Composites during Hot Working. International Journal of Mechanical \& Mechatronics Engineering IJMME-IJENS Vol:15 No:04. pp. 74-79.

2. E. Doege, R. Bohnsack. Closed die technologies for hot forging. Journal of Materials Processing Technology 98 (2000). pp. $165-170$

3. Hyoungwoo Lee, Seokhwan Ahn. Prediction of the Mechanical Properties of the Main Shaft of a Wind Power Generator made out of 34CrNiMo6M Steel Considering the Mass Effect. International Journal of Mechanical \& Mechatronics Engineering IJMME-IJENS Vol:19 No:03. pp 1-9. 
4. Kaur, Jasleen, B S Pabla, and S S Dhami. "A Parametric Analysis of Deformation of Workpiece, in Closed Die Forging."International Journal of Mechanical and Production Engineering Research and Development (IJMPERD) 7, Dec 2017, 147-154

5. E. Giarmas1, D. Tzetzis. Experimental and Finite Element Analysis of Severing the Butt Ends of Aluminum Billets During the Extrusion Process. International Journal of Mechanical \& Mechatronics Engineering IJMME-IJENS, Vol:18 No:03. pp. 1824.

6. Soundararajan, R., et al. "Effect of die sleeve material on mechanical behavior of A413 aluminium alloy processed through squeeze casting route." Int J Mech Prod Eng Res Dev 8.3 (2018): 583-590.

7. E. S. Abdelghany. CFD Investigation for Effect of the Aerodynamic Truck - Cabin Profiles and Devices on the Truck Performance. International Journal of Mechanical \& Mechatronics Engineering IJMME-IJENS Vol:20 No:03. pp 1-17.

8. Kumar, Pankaj, and J. Harivignesh. "Grain Refinement Through Design Modification of ECAP Dies." International Journal of Mechanical and Production Engineering Research and Development (IJMPERD) 8.1 (2018): 35-42.

9. Mohamed Elkeran, Mohamed Fanni, and Hiroyasu Iwata. Material Modeling and Development of Soft Surgical Robots Using Transient Finite Element Analysis. International Journal of Mechanical \& Mechatronics Engineering IJMME-IJENS Vol:20 No:01. pp 25-34.

10. Marwan T. Mezher, Mursal Luaibi Saad, Osamah Sabah Barrak3, Rusul Ahmed Shakir. Finite Element Simulation and Experimental Analysis of Nano Powder Additives Effect in the Deep Drawing Process.International Journal of Mechanical \& Mechatronics Engineering IJMME-IJENS Vol:20 No:01. pp 166-180.

11. Tan Xie, 1998. Development of Precision Forged Gear Technology in China. International Conference on Forging and Related Technologies (ICFT' 98), April 28-29, Birmingham, UK. pp. 323-331.

12. Soundararajan, R., et al. "Effect of squeeze casting process parameters on surface roughness of A413 alloy and A413-B4C composites." Int J Mech Prod Eng Res Dev 8.2 (2018): 1157-1166.

13. L.-J. Cheng et al., FEM simulation of forging process for the design of a rear axle bracket, Journal of Plasticity Engineering. $2008-01$.

14. Lianjun Cheng et al. The new preforging method of closed-die forging with controlled-flash for steering knuckles; Advanced Materials Research Vols. 482-484 (2012). pp. 2409-2413.

15. Tahir Altinbalik et al.An approach for calculation of press loads in closed - die upsetting of gear blanks of gear pumps, Materials and Design 28(2).pp. 730-734.

16. Yong-Jin Choi et al, Hot forging process design of sprocket wheel and environmental effect analysis, Journal of Mechanical Science and Technology 32 (5) (2018). pp. 2219 222.

17. Lianjun Cheng, Tiezhu Zhang and Hongxin Zhang. The new preforging method of closed-die forging with controlled-flash for steering knuckles. Advanced Materials Research Vols. $482-484$ (2012). pp. 2409-2413.

18. Duggirala, R., Shivpuri, R., Kini, S., Ghosh, S. and Roy, S. 1994. Computer aided approach for design and optimization of cold forging sequences for automotive parts. Journal of Materials Processing Technology 46 (12). pp. 185-198.

19. Behrens, B.-A., Doege, E., Reinsch, S., Telkamp, K., Daehndel, H., and Specker, A. 2007. Precision Forging Processes for High-duty Automotive Components. Journal of Materials Processing Technology 185. pp. 139-46.

20. Song, J. H., Im, Y. T. 2007. Process design for closed-die forging of bevel gear by finite element analyses, Journal of Materials Processing Technology. pp. 192-193 1-7. 
21. Dean, T.A., Eyercioglu, Ö., 1997. Design and Manufacture of Precision Gear Forging Dies. International Conference and Exhibition on Design and Production of dies and Moulds, June 19+21, Instanbul, Turkey: pp. 311 - 316.

22. Lange, K., Cser, L., Geiger, M., \& Kals, J. A. G. (1992). Tool life and tool quality in bulk metal forming. CIRP annals, 41(2). pp. 667-675.

23. Nikolai Biba, Hendrik Muntinga, Sergey stebunov. Increasing of tool life in cold forging by means of FEM simulation. 2005. https://www.researchgate.net.

24. Siamak Abachi, Metin Akkok, Mustafa ilhan Gokler. Wear analysis of hot forging dies. Tribology International 43 (2010). pp. 467-473

25. H.M.T. Khaleed, Z. Samad, A.R. Othman, M.A. Mujeebu, A.B. Abdullah, N.J. S. Ahmed and M.M.Zihad. Flash-less cold forging and temperature distribution in forged autonomous underwater vehicle hubs using fem analysis and experimental validation. International Journal of Mechanical and Materials Engineering (IJMME), Vol.6 (2011), No.2. pp. 291-299 